\title{
MECHANISMS OF STRESS CORROSION CRACKING
}

\author{
Spisák Bernadett ${ }^{1}$, Szávai Szabolcs ${ }^{2}$ \\ ${ }^{1} \mathrm{PhD}$ student, ${ }^{2} \mathrm{PhD}$, Head of Department \\ ${ }^{1}$ University of Miskolc Department of Chemical Machinery, ${ }^{2}$ Bay Zoltán Nonprofit \\ Ltd. for Applied Research
}

\section{INTRODUCTION}

Stress corrosion cracking (SCC) even nowadays is the cause of significant service failures, it can occur in almost any type of components of the chemical industry such as steam generator tubes, pressurizer instrument penetrations and heater sleeves, control rod drive mechanism (CRDM) nozzles, heat exchangers [1]-[6]. One of the most recent major accident happened in 2009, where a 50 -foot-tall highpressure vessel ruptured, resulting in one fatality and one injury of the public. Based on the review of the National Institute of Standards and Technology the failure was caused by the combination of stress corrosion cracking and a reduction in material toughness during service [6]. In case of existing nuclear power plants the stress corrosion cracking counts as one of the important ageing degradations. For stress corrosion to occur three indispensable factors have to be present, which are the tensile stress, the environment and the susceptible material. If changes are made in any of these factors then the susceptibility to SCC often can be eliminated or reduced. The tensile stress can originate from residual stresses, operational loadings, the structural and metallurgical factors includes the degree of grain size, thermal treatment, cold work, and finally the environment factors are resulted from the water chemistry, the operating temperature [1]. However this type of failure is sudden and difficult to predict and also material properties may change with time or due to material processing. Therefore the right way of prediction and modelling of SCC is still a vital research area. In this article the different type of SCC mechanisms are presented, the ones used in the nuclear industry in more details.

\section{STRESS CORROSION CRACKING MECHANISMS}

Stress corrosion cracking of materials occurs because of the combined action of continuous mechanical load and electrochemical corrosion. Based on this knowledge several types of SCC mechanisms have been suggested so far. These can be sorted as electrochemical and electrochemical-mechanical mechanisms. These methods have their own benefits and disadvantages and in the followings the main properties are going to be discussed in more details. The more important ones are listed below:

- Slip dissolution/film rupture mechanism (Ford and Andersen) [7]

- Enhanced surface mobility theory (Galvele) [9]

- Coupled environment fracture model - CEFM (Macdonald and UrquidiMacdonald) [8]

- Internal oxidation model (Scott) [11]-[13]

- Selective dissolution - vacancy creep model (Aaltonen) [14] 
- Flim induced cleavage model (Paskin, Seradzki, Newman) [15][16]

- Hydrogen based mechanism

\section{Slip dissolution/film rupture mechanism}

In the case of nuclear industry one of the most used models for SCC is the slip dissolution/film rupture mechanism, it was developed by Ford and Andersen. They assumed that the steps of the primary mechanism of SCC are the film formation, film rupture, material removal and subsequent film repassivation. The model was mainly developed for stainless steels which are in boiling water nuclear reactors (BWR). It depends from the crack tip strain rate, the charge oxidation density and the stress intensity factors, which are factors of the crack tip region. The crack tip growth rate is given through the following equation:

$$
v_{c t}=\frac{M}{z \rho F} \frac{Q_{f}}{\varepsilon_{f}}\left(\frac{d \varepsilon}{d t}\right)_{c t}
$$

where: $v_{c t}$ is the crack tip growth rate, $M$ is the molecular weight of the material, $z$ is the charge of the anodic dissolved material, $\rho$ is the material density, $F$ is the Faraday constant, $Q_{f}$ is charge density per film rupture event, $\varepsilon_{f}$ is the oxide fracture strain, and $(d \varepsilon / d t)_{c t}$ is the crack tip strain rate [7].

\section{Enhanced surface mobility theory}

The main feature of this mechanism is that the atoms transports from the crack tip with surface diffusion. The atoms moves from the highly stressed crack tip to the less stressed sides. This model was developed by Galvele in 1987. His belief was that the oxidation currents at the crack tip do not explain the high crack growth rates. The base of this model is the embrittlement mechanism, and it can also be used to characterize the hydrogen embrittlement [9].

\section{Coupled environment fracture model - CEFM}

The model was developed by Macdonald and Urquidi-Macdonald [8]. The model was created for calculating the crack growth rate in sensitized Type 304SS. The mechanism of the crack advance is based on the previously introduced slip dissolution/film rupture model, however this version takes into account the differential aeration hypothesis (DAH) therefore it includes the charge conservation, which results in the coupling of internal and external environments. The schematics illustration of CEFM can be seen on the 1. Figure. Even though this theory is an empirical model, it tries to connect the two crack environments. The model assumes the followings:

- With the increase of stress intensity the potential at the tip increases, however it is not affected at the crack mouth;

- In case of the oxygen concentration it is the inverse of this, therefore the tip is unaffected and the crack mouth is influenced; 
- The crack growth rate is no affected by the $\mathrm{pH}$ and temperature; they influence the potential difference between the crack tip and the external environment.

One of the modification of this method was used also for Alloy 600 operating in PWR. Shi et al. developed this version where the results contains quantitative prediction of the effects of hydrogen concentration, yield strength, stress intensity factor and temperature on crack growth [10].

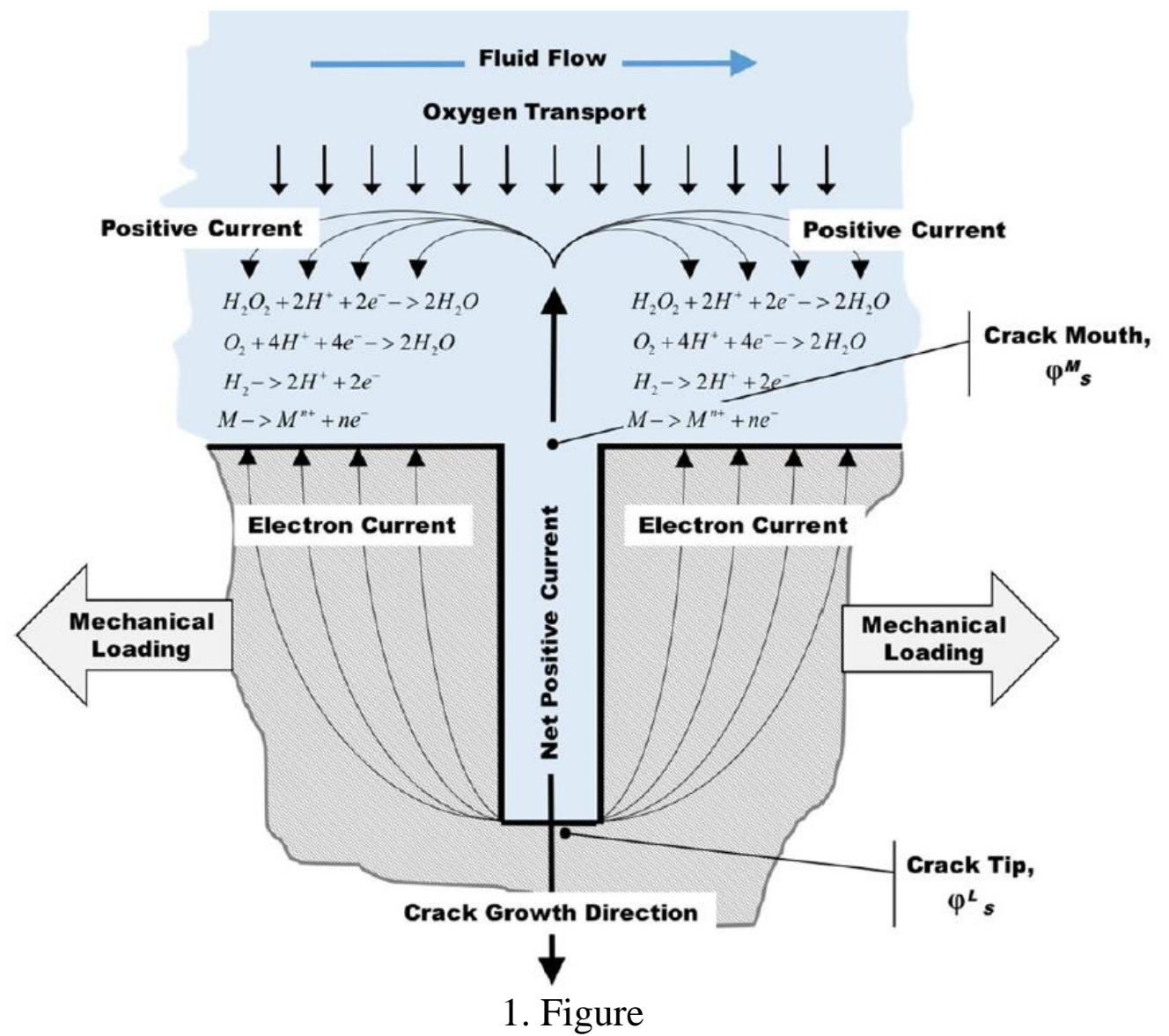

Shematic presentation of CEFM [10]

\section{Internal oxidation model}

The internal oxidation model developed by P. M.Scott and M. Le Calvar [11][13] is an empirical solution which is applicable to the nickel alloys used in the pressurized water nuclear reactors (PWR). The basis of the model is the embrittlement mechanism, where the created formulas depend from the threshold stress intensity factor. The following model equation is made according of his mechanism, and shows the crack growth rate.

$$
v_{I G S C C}=\left(\frac{81 k T D_{0}}{512 \gamma^{3} a^{2}}\right)\left(\frac{\delta N_{S}}{6 \pi z}\right)^{1 / 2} \sigma_{p} K_{I}
$$

Where:

- $v_{I G S C C}$ : intergranular stress corrosion crack growth rate 
- $\quad k$ : Boltzmann constant

- $\quad T$ : absolute temperature

- $D_{0}$ : grain boundary diffusion coefficient for oxygen in considered material

- $\gamma$ : surface energy

- $a$ : atomic volume

- $\delta$ : grain boundary width

- $N_{S}$ : surface solubility of the oxygen

- $\quad z$ : number of sites explored per gas atom jump

- $\sigma_{p}$ : stress contour of the plane strain plastic zone radius of the process crack zone

- $K_{I}$ : crack tip stress intensity factor

\section{RECENT MODELLINGS OF SCC}

Numerical modelling has become a widely used analysis technique in the engineering world, therefore also in case of the stress corrosion cracking numerous models have been made, and are still being developed. In the following some of these methods are going to be introduced. Jivkov et al. [17] made the first significant attempt in using the finite element methods for SCC; they modelled the mechanical effects of stress in intergranular stress corrosion cracking, where the basic material was Type 304 stainless steel. The introduced work includes a model of the microstructure and a strategy for crack advance. The results shown proved that the finite element method is usable when the process beside the mechanical effect contains chemical or corrosion based factors too.

Nikishkov et al. [18][19] beside the finite element method used the symmetric Galerkin boundary element method (SGBEM). The stress analysis of the uncracked structural component is defined with the FE model while the crack is characterised with the SGBEM. The authors proved that this model applicable to the simulation of SCC in case of surface cracks and short through-thickness cracks.

In another approach of stress corrosion cracking modelling the phase field method was applied. The first attempt was made by Sahle and Hansen [20]. Their aim was to have a better understanding about the initiation of cracking from surface roughness or pitting. They proved that stress corrosion can be modelled as a moving boundary problem although they did not consider the metal dissolution as a conservative process and thereby does not incorporate the mass transport in the formulation, Based on this method Nguyen et al. [21]-[23] developed a new formulation for modelling SCC. The model is based on the slip dissolution mechanism; however it also combines the electrochemical and mechanical processes. It simulates the effects of SCC on fracture mechanics. The predictions of the crack morphology is in accordance with the experimental result, however with the increasing the size of the analysed structure some incoherence can be detected, which is caused by the lack of microstructure details. A second example is given by Mai and Soghrati [24]. They also used the phase field method for stress corrosion cracking. In their study the crack is initiated from pits and they adopted the film rupture-dissolution-repassivation model, which couples the interface kinetics parameter to the stress intensity factor and the stress distribution near the crack tip. 
The results were in agreement with the SCC growth rates predicted by empirical models.

A new procedure was proposed by Couvant et al [25]-[27], who developed a "local" model. The intergranular oxidation rate, the intergranular stresses, resistance to cracking of oxidized grain boundaries were integrated in it and calibrations were made. There are two meaning of local in the model. In the incubation and initiation phase of SCC "local" refers to grain boundary, however when cracking occurs it changes to the intergranular crack tip. The calibration of the local model is simpler than other empirical model's. However it still does not contain the influence of the surface finish and the accuracy of the cracking criteria of oxidized grain boundaries and the cracking kinetics in the slow crack growth regime is still lacking.

\section{SUMMARY}

In the article the different kind of mechanism and modelling methods were introduced. Stress corrosion cracking is a very complex failure mechanism; therefore the prediction of it is a very difficult task. A large part of the shown methods were empirical models as based on the environment and material the SCC behaviour varies within a wide range. In the last few years developed models are giving a better picture about this failure method, however there are still several unanswered question in this topic.

\section{ACKNOWLEDGEMENT}

The described article/presentation/study was carried out as part of the EFOP-3.6.116-2016-00011 "Younger and Renewing University - Innovative Knowledge City institutional development of the University of Miskolc aiming at intelligent specialisation" project implemented in the framework of the Szechenyi 2020 program. The realization of this project is supported by the European Union, cofinanced by the European Social Fund.

[1] INTERNATIONAL ATOMIC ENERGY AGENCY: Stress Corrosion Cracking in Light Water Reactors: Good Practices and Lessons Learned, Nuclear Energy Series No. NP-T-3.13, IAEA, Vienna, 2011

[2] PETRIK, M., SZEPESI, G:L:, ; VARGA, T.: Numerical and Experimental Study of Finned Tube Heat Transfer Characteristics, LECTURE NOTES IN MECHANICAL ENGINEERING 2018 pp. 563-570.

[3] MIKÁCZÓ, V., SZEPESI, G.; SIMÉNFALVI, Z.: Simulation of Propane explosion in closed vessel, Annals of Faculty Engineering Hunedoara International Journal of Engineering 152017

[4] SINGH; B., SIMÉNFALVI; Z., SZAMOSI, Z.: Designing of Lab-scale anaerobic digester equipped with Maxblend impeller to evaluate effect of mixing on anaerobic digestion, Proceedings of the 6th International Scientific Conference on Advances in Mechanical Engineering Debrecen 2018 
[5] GORMAN, J.A.:2015 Frank Newman Speller Award: Stress Corrosion Cracking and Nuclear Power, https://doi.org/10.5006/1898, Corrosion, Vol. 71, 2015, Pages 1414-1433

[6] ZHANG, J., LABOUREUR, D., LIU, Y., MANNAN, M. S.: Lessons learned from a supercritical pressure BLEVE in Nihon Dempa Kogyo Crystal Inc. Journal of Loss Prevention in the Process Industries, Volume 41, 2016, Pages 315-322

[7] ANDERSEN, P.L., FORD, F.P.: Life Prediction by Mechanistic Modeling and System Monitoring of Environmental Cracking of Iron and Nickel Alloys in Aqueous Systems*, Materials Science and Engineering, A 103, 1988, Pages 167-184

[8] MACDONALD, D.D., URQUIDI-MACDONALD, M.: A coupled environment model for stress corrosion cracking in sensitized type 304 stainless steel in LWR environments, Corr. Sci. 32, 1991, Pages 51-81.

[9] GALVELE, J.R.: Application of the surface-mobility stress corrosion cracking mechanism to nuclear materials, Journal of Nuclear Materials, Vol. 229, 1996, pp.139-148.

[10] SHI, J., FEKETE, B., WANG, J, MACDONALD, D.D.: Customization of the coupled environment fracture model for predicting stress corrosion cracking in Alloy 600 in PWR environment, Corr. Sci. 139, 2018, 58-67

[11] SCOTT, P.M., LE CALVAR, M., Some possible mechanisms of intergranular stress corrosion cracking of alloy 600 in PWR primary water, In.: Proc. 6th Int. Symp. On Environmental Degradation of Materials in Nuclear Power Systems Water Reactors, 1993, p. 657.

[12] GUELlOUH, N., SISODIA, R. P. S., SZAMOSI Z.: The weldability of high strength steels, Multiscience XXXII. MicroCAD International Multidisciplinary Scientific Conference, Miskolc, 2018

[13] SCOTT, P.M.: An Overview of Internal Oxidation as a Possible Explanation of Intergranular Stress Corrosion Cracking of Alloy 600 in PWRS, https://doi.org/10.1002/9781118787618.ch1, Ninth International Symposium on Environmental Degradation of Materials in Nuclear Power Systems-Water Reactors, 2013, 3-15

[14] AALTONEN, P., SAARIO, T., KARJALAINEN-ROIKONEN, P., PIPPO, J., TAHTITEN, S., ITAAHO, M., HANNINEN, H.: Vacancy-creep model for EAC of metallic materials in high temperature water, Proceedings of Corrosion '96 conference, NACE Internatioal 1996, paper no. 81

[15] PASKIN, A., SIERADZKI, K., SOM, D.K., DIENES, G.J.: Environmentally induced crack nucleation and brittle structure, Acta metal., 30, 1982, pp. 1781-1788

[16] SIERADZKI, K., NEMAN, R.C.: Brittle behaviour of ductile metals during stress-corrosion cracking, Philosophical Magazine A 51, 1985, pp 95-132

[17] JIVKOV, A.P., STEVENS, N.P.C., MARROW, T.J.: A three-dimensional computational model for intergranular cracking, Computational Material Science, Volume 38, Issue 2, 2006, Pages 442-453 
[18] NIKISHKOV, G.P.: SGBEM-FEM Modeling of Stress Corrosion Cracking, 16th Pacific Basin Nuclear Conference (16PBNC), Aomori, Japan, Oct. 13-18, 2008

[19] PARK, J. H., NIKISHKOV, G.P.: Growth simulation for 3D surface and through-thickness cracks using SGBEM-FEM alternating method, Journal of Mechanical Science and Technology 25 (9), 2011, 2335-2344

[20] STAHLE, P., HANSEN, E.: Phase field modelling of stress corrosion, Engineering Failure Analysis, 47, 2015, Pages 241-251

[21] NGUYEN, T.T., BOLIVAR, J., RÉTHORÉ, J., BAIETTO, M-C: A phase field method for modeling stress corrosion crack propagation in a nickel base alloy, International Journal of Solids and Structures, 112, 2017, Pages 65-82

[22] NGUYEN, T.T., RÉTHORÉ, J., BAIETTO, M-C, BOLIVAR, J.,FREGONESE, M.: A phase field method for modeling stress corrosion crack propagation induced by anodic dissolution, 14th International Conference on Fracture, Rhodes, Greece, 2017

[23] NGUYEN, T.T., BOLIVAR, J., SHI, Y., RÉTHORÉ, J., KING, A., FREGONESE, M., ADRIEN, J., BUFFIERE, J-Y., BAIETTO, M-C.: A phase field method for modeling anodic dissolution induced stress corrosion crack propagation, Corrosion Science 132, 2018, Pages 146-160

[24] MAI, W., SOGHRATI, S.: A phase field model for simulating the stress corrosion cracking initiated from pits, Corrosion Science, 12, 2017, Pages 87-98

[25] COUVANT, T., WEHBI, M., DUHAMEL, C., CRÉPIN, J., MUNIER, R.: Development of a local model to predict SCC: preliminary calibration of parameters for nickel alloys exposed to primary water, 17th International Conference on Environmental Degradation of Materials in Nuclear SystemsWater Reactors, Ottawa (Canada), 2015

[26] COUVANT, T., CABAllero, J., DUHAMEL, C., CRÉPIN, J., MAEGUCHI, T.: Calibration of the Local IGSCC Engineering Model for Alloy 600, 18th International Conference on Environmental Degradation of Materials in Nuclear Systems-Water Reactors, The Minerals, Metals \& Materials Society 2019

[27] COUVANT, T.: Prediction of IGSCC as a Finite Element Modeling Postanalysis, 18th International Conference on Environmental Degradation of Materials in Nuclear Systems-Water Reactors, The Minerals, Metals \& Materials Society 2019 